\title{
Ostrowski-type inequalities via $h$-convex functions with applications to special means
}

Mevlüt Tunç*

\section{"Correspondence:}

mevluttunc@kilis.edu.tr

Department of Mathematics,

Faculty of Science and Arts, Kilis 7

Aralık University, Kilis, 79000, Turkey

\begin{abstract}
In this paper, we establish some new Ostrowski-type inequalities for absolutely continuous mappings whose first derivatives in absolute value are $h$-convex (resp. $h$-concave) and which are super-multiplicative or super-additive. Some applications to special means are given.
\end{abstract}

MSC: 26D10; 26A15; 26A16; 26A51

Keywords: Ostrowski's inequality; $h$-convex; super-multiplicative; super-additive

\section{Introduction}

[1] Let $f: I \subset[0, \infty) \rightarrow \mathbb{R}$ be a differentiable mapping on $I^{\circ}$, the interior of the interval $I$, such that $f^{\prime} \in L[a, b]$, where $a, b \in I$ with $a<b$. If $\left|f^{\prime}(x)\right| \leq M$, then the following inequality holds:

$$
\left|f(x)-\frac{1}{b-a} \int_{a}^{b} f(u) d u\right| \leq \frac{M}{b-a}\left[\frac{(x-a)^{2}+(b-x)^{2}}{2}\right] .
$$

This result is known in the literature as the Ostrowski inequality. For recent results and generalizations concerning Ostrowski's inequality, see [2-7] and the references therein.

Definition 1 [8] We say that $f: I \rightarrow \mathbb{R}$ is a Godunova-Levin function or that $f$ belongs to the class $Q(I)$ if $f$ is nonnegative, and for all $x, y \in I$ and $t \in(0,1)$, we have

$$
f(t x+(1-t) y) \leq \frac{f(x)}{t}+\frac{f(y)}{1-t} .
$$

Definition 2 [9] We say that $f: I \subseteq \mathbb{R} \rightarrow \mathbb{R}$ is a $P$-function, or that $f$ belongs to the class $P(I)$, if $f$ is nonnegative, and for all $x, y \in I$ and $t \in[0,1]$, we have

$$
f(t x+(1-t) y) \leq f(x)+f(y) .
$$

Definition $3[10]$ Let $s \in(0,1]$. A function $f:[0, \infty) \rightarrow[0, \infty)$ is said to be $s$-convex in the second sense if

$$
f(t x+(1-t) y) \leq t^{s} f(x)+(1-t)^{s} f(y)
$$

for all $x, y \in[0, \infty)$ and $t \in[0,1]$. This class of $s$-convex functions is usually denoted by $K_{s}^{2}$.

\section{Springer}

2013 Tunç: licensee Springer. This is an Open Access article distributed under the terms of the Creative Commons Attribution License (http://creativecommons.org/licenses/by/2.0), which permits unrestricted use, distribution, and reproduction in any medium, provided the original work is properly cited. 
Definition 4 [11] Let $h: J \rightarrow \mathbb{R}$ be a nonnegative function, $h \not \equiv 0$. We say that $f: I \subseteq \mathbb{R} \rightarrow$ $\mathbb{R}$ is an $h$-convex function, or that $f$ belongs to the class $S X(h, I)$, if $f$ is nonnegative, and for all $x, y \in I$ and $t \in[0,1]$, we have

$$
f(t x+(1-t) y) \leq h(t) f(x)+h(1-t) f(y) .
$$

If inequality (1.5) is reversed, then $f$ is said to be $h$-concave, i.e., $f \in S V(h, I)$. Obviously, if $h(t)=t$, then all nonnegative convex functions belong to $S X(h, I)$ and all nonnegative concave functions belong to $S V(h, I)$; if $h(t)=\frac{1}{t}$, then $S X(h, I)=Q(I)$; if $h(t)=1$, then $S X(h, I) \supseteq P(I)$; and if $h(t)=t^{s}$, where $s \in(0,1)$, then $S X(h, I) \supseteq K_{s}^{2}$.

Remark 1 [11] Let $h$ be a nonnegative function such that

$$
h(\alpha) \geq \alpha
$$

for all $\alpha \in(0,1)$. For example, the function $h_{k}(x)=x^{k}$, where $k \leq 1$ and $x>0$, has that property. If $f$ is a nonnegative convex function on $I$, then for $x, y \in I, \alpha \in(0,1)$, we have

$$
f(\alpha x+(1-\alpha) y) \leq \alpha f(x)+(1-\alpha) f(y) \leq h(\alpha) f(x)+h(1-\alpha) f(y) .
$$

So, $f \in S X(h, I)$. Similarly, if the function $h$ has the property $h(\alpha) \leq \alpha$ for all $\alpha \in(0,1)$, then any nonnegative concave function $f$ belongs to the class $S V(h, I)$.

Definition 5 [11] A function $h: J \rightarrow \mathbb{R}$ is said to be a super-multiplicative function if

$$
h(x y) \geq h(x) h(y)
$$

for all $x, y \in J$, when $x y \in J$.

If inequality (1.8) is reversed, then $h$ is said to be a sub-multiplicative function. If equality is held in (1.8), then $h$ is said to be a multiplicative function.

Definition 6 [12] A function $h: J \rightarrow \mathbb{R}$ is said to be a super-additive function if

$$
h(x+y) \geq h(x)+h(y)
$$

for all $x, y \in J$, when $x+y \in J$.

In [13], Sarıkaya et al. established the following Hadamard-type inequality for $h$-convex functions.

Theorem 1 [13] Let $f \in S X(h, I), a, b \in I$ and $f \in L_{1}([a, b])$, then

$$
\frac{1}{2 h\left(\frac{1}{2}\right)} f\left(\frac{a+b}{2}\right) \leq \frac{1}{b-a} \int_{a}^{b} f(x) d x \leq[f(a)+f(b)] \int_{0}^{1} h(t) d t .
$$

For recent results related to $h$-convex functions, see $[11,13-16]$.

The aim of this study is to establish some Ostrowski-type inequalities for the class of functions whose derivatives in absolute value are $h$-convex and $h$-concave functions. 


\section{Ostrowski-type inequalities for $\boldsymbol{h}$-convex functions}

In order to achieve our objective, we need the following lemma [5].

Lemma 1 [5] Let $f: I \subseteq \mathbb{R} \rightarrow \mathbb{R}$ be a differentiable mapping on $I^{\circ}$ where $a, b \in I$ with $a<b$. If $f^{\prime} \in L[a, b]$, then the following equality holds:

$$
\begin{aligned}
f(x) & -\frac{1}{b-a} \int_{a}^{b} f(u) d u \\
& =\frac{(x-a)^{2}}{b-a} \int_{0}^{1} t f^{\prime}(t x+(1-t) a) d t-\frac{(b-x)^{2}}{b-a} \int_{0}^{1} t f^{\prime}(t x+(1-t) b) d t
\end{aligned}
$$

for each $x \in[a, b]$.

Theorem 2 Let $h: J \subseteq \mathbb{R} \rightarrow \mathbb{R}$ be a nonnegative and super-multiplicative function, let $f: I \subseteq \mathbb{R} \rightarrow \mathbb{R}$ be a differentiable mapping on $I^{\circ}$ such that $f^{\prime} \in L[a, b]$, where $a, b \in I$ with $a<b$, and $h(\alpha) \geq \alpha$. If $\left|f^{\prime}\right|$ is an h-convex function on I and $\left|f^{\prime}(x)\right| \leq M, x \in[a, b]$, then we have

$$
\left|f(x)-\frac{1}{b-a} \int_{a}^{b} f(u) d u\right| \leq \frac{M\left[(x-a)^{2}+(b-x)^{2}\right]}{b-a} \int_{0}^{1}\left[h\left(t^{2}\right)+h\left(t-t^{2}\right)\right] d t
$$

for each $x \in[a, b]$.

Proof By Lemma 1 and since $\left|f^{\prime}\right|$ is $h$-convex, then we can write

$$
\begin{aligned}
\mid f(x) & -\frac{1}{b-a} \int_{a}^{b} f(u) d u \mid \\
\leq & \frac{(x-a)^{2}}{b-a} \int_{0}^{1} t\left|f^{\prime}(t x+(1-t) a)\right| d t+\frac{(b-x)^{2}}{b-a} \int_{0}^{1} t\left|f^{\prime}(t x+(1-t) b)\right| d t \\
\leq & \frac{(x-a)^{2}}{b-a} \int_{0}^{1} t\left[h(t)\left|f^{\prime}(x)\right|+h(1-t)\left|f^{\prime}(a)\right|\right] d t \\
& +\frac{(b-x)^{2}}{b-a} \int_{0}^{1} t\left[h(t)\left|f^{\prime}(x)\right|+h(1-t)\left|f^{\prime}(b)\right|\right] d t \\
\leq & \frac{M(x-a)^{2}}{b-a} \int_{0}^{1}\left[h^{2}(t)+h(t) h(1-t)\right] d t \\
& +\frac{M(b-x)^{2}}{b-a} \int_{0}^{1}\left[h^{2}(t)+h(t) h(1-t)\right] d t \\
\leq & \frac{M\left[(x-a)^{2}+(b-x)^{2}\right]}{b-a} \int_{0}^{1}\left[h\left(t^{2}\right)+h\left(t-t^{2}\right)\right] d t .
\end{aligned}
$$

The proof is completed.

Remark 2 In (2.1), if we choose $h(t)=t$, inequality (2.1) reduces to (1.1).

In the next corollary, we also make use of the beta function of Euler type, which is for $x, y>0$ defined as

$$
\beta(x, y)=\int_{0}^{1} t^{x-1}(1-t)^{y-1} d t=\frac{\Gamma(x) \Gamma(y)}{\Gamma(x+y)} .
$$


Corollary 1 In (2.1), if we choose $h(t)=t^{s}$, then we have

$$
\begin{aligned}
\mid f(x) & -\frac{1}{b-a} \int_{a}^{b} f(u) d u \mid \\
& \leq \frac{M\left[(x-a)^{2}+(b-x)^{2}\right]}{b-a} \int_{0}^{1}\left[t^{2 s}+\left(t-t^{2}\right)^{s}\right] d t \\
& =\frac{M\left[(x-a)^{2}+(b-x)^{2}\right]}{b-a} \int_{0}^{1}\left[t^{2 s}+t^{s}(1-t)^{s}\right] d t \\
& =\frac{M\left[(x-a)^{2}+(b-x)^{2}\right]}{b-a}\left[\frac{1}{2 s+1}+\frac{\Gamma(s+1) \Gamma(s+1)}{\Gamma(2 s+2)}\right] \\
& =\frac{M\left[(x-a)^{2}+(b-x)^{2}\right]}{b-a}\left[\frac{\Gamma(2 s+1)+s^{2}(\Gamma(s))^{2}}{(2 s+1) \Gamma(2 s+1)}\right] .
\end{aligned}
$$

One of the important results is given in the following theorem.

Theorem 3 Let $h: J \subseteq \mathbb{R} \rightarrow \mathbb{R}$ be a nonnegative and super-additive function, let $f: I \subseteq$ $\mathbb{R} \rightarrow \mathbb{R}$ be a differentiable mapping on $I^{\circ}$ such that $f^{\prime} \in L[a, b]$, where $a, b \in I$ with $a<b$. If $\left|f^{\prime}\right|^{q}$ is an $h$-convex function on $[a, b], p, q>1, \frac{1}{p}+\frac{1}{q}=1, h(t) \geq t$ and $\left|f^{\prime}(x)\right| \leq M, x \in[a, b]$, then

$$
\left|f(x)-\frac{1}{b-a} \int_{a}^{b} f(u) d u\right| \leq \frac{M h^{\frac{1}{q}}(1)}{b-a}\left(\int_{0}^{1}\left(h\left(t^{p}\right) d t\right)\right)^{\frac{1}{p}}\left((x-a)^{2}+(b-x)^{2}\right)
$$

for each $x \in[a, b]$.

Proof Suppose that $p>1$. From Lemma 1 and using Hölder's inequality, we can write

$$
\begin{aligned}
\mid f(x) & -\frac{1}{b-a} \int_{a}^{b} f(u) d u \mid \\
\leq & \frac{(x-a)^{2}}{b-a} \int_{0}^{1} t\left|f^{\prime}(t x+(1-t) a)\right| d t+\frac{(b-x)^{2}}{b-a} \int_{0}^{1} t\left|f^{\prime}(t x+(1-t) b)\right| d t \\
\leq & \frac{(x-a)^{2}}{b-a}\left(\int_{0}^{1} t^{p} d t\right)^{\frac{1}{p}}\left(\int_{0}^{1}\left|f^{\prime}(t x+(1-t) a)\right|^{q} d t\right)^{\frac{1}{q}} \\
& +\frac{(b-x)^{2}}{b-a}\left(\int_{0}^{1} t^{p} d t\right)^{\frac{1}{p}}\left(\int_{0}^{1}\left|f^{\prime}(t x+(1-t) b)\right|^{q} d t\right)^{\frac{1}{q}} .
\end{aligned}
$$

Since $\left|f^{\prime}\right|^{q}$ is $h$-convex, by using the properties of $h$-convexity in the assumptions, we have

$$
\begin{aligned}
\int_{0}^{1}\left|f^{\prime}(t x+(1-t) a)\right|^{q} d t & \leq \int_{0}^{1}\left[h(t)\left|f^{\prime}(x)\right|^{q}+h(1-t)\left|f^{\prime}(a)\right|^{q}\right] d t \\
& \leq M^{q} \int_{0}^{1}[h(t)+h(1-t)] d t \\
& \leq M^{q} \int_{0}^{1} h(1) d t=M^{q} h(1) .
\end{aligned}
$$


Similarly, we can show that

$$
\begin{aligned}
\int_{0}^{1}\left|f^{\prime}(t x+(1-t) b)\right|^{q} d t & \leq \int_{0}^{1}\left[h(t)\left|f^{\prime}(x)\right|^{q}+h(1-t)\left|f^{\prime}(b)\right|^{q}\right] d t \\
& \leq M^{q} h(1)
\end{aligned}
$$

and

$$
\int_{0}^{1} t^{p} d t \leq \int_{0}^{1} h\left(t^{p}\right) d t
$$

Therefore, we obtain

$$
\begin{aligned}
\left|f(x)-\frac{1}{b-a} \int_{a}^{b} f(u) d u\right| \leq & M h^{\frac{1}{q}}(1) \frac{(x-a)^{2}}{b-a}\left(\int_{0}^{1} h\left(t^{p}\right) d t\right)^{\frac{1}{p}} \\
& +M h^{\frac{1}{q}}(1) \frac{(b-x)^{2}}{b-a}\left(\int_{0}^{1} h\left(t^{p}\right) d t\right)^{\frac{1}{p}} \\
= & \frac{M h^{\frac{1}{q}}(1)}{b-a}\left(\int_{0}^{1} h\left(t^{p}\right) d t\right)^{\frac{1}{p}}\left((x-a)^{2}+(b-x)^{2}\right) .
\end{aligned}
$$

The proof is completed.

For example, $h(t)=t^{2}$ is a super-additive function for nonnegative real numbers because the square of $(u+v)$ is always greater than or equal to the square of $u$ plus the square of $v$, for $u, v \in[0, \infty)$.

Corollary 2 In (2.2), if we choose $h(t)=t^{n}$ with $n \in \mathbb{N}, n \geq 2$, then we have

$$
\left|f(x)-\frac{1}{b-a} \int_{a}^{b} f(u) d u\right| \leq \frac{M}{b-a}\left(\frac{1}{n p+1}\right)^{\frac{1}{p}}\left((x-a)^{2}+(b-x)^{2}\right) .
$$

Remark 3 Since $\left(\frac{1}{n p+1}\right)^{\frac{1}{p}}<\frac{1}{2}$, for any $4 \geq n>p>1, n \in \mathbb{N}$, then we behold that inequality (2.3) is better than inequality (1.1). Better approaches can be obtained even if it is irregular for bigger $n$ and $p$ numbers.

As we know, $h$-convex functions include all nonnegative convex, $s$-convex in the second sense, $Q(I)$-convex and $P$-convex function classes. In this respect, it is normal to obtain weaker results once compared with inequalities in referenced studies, because the inequalities written herein were considered to be more general than the above-mentioned classes, and it was taken into account to be super-multiplicative or super-additive material. In this case, the right side of inequality may be greater.

A new approach to an $h$-convex function is given in the following result.

Theorem 4 Let $h: J \subseteq \mathbb{R} \rightarrow \mathbb{R}$ be a nonnegative and super-multiplicative function, let $f: I \subseteq \mathbb{R} \rightarrow \mathbb{R}$ be a differentiable mapping on $I^{\circ}$ such that $f^{\prime} \in L[a, b]$, where $a, b \in I$ with $a<b$. If $\left|f^{\prime}\right|^{q}$ is an h-convex function on $[a, b], q \geq 1, h(\alpha) \geq \alpha$ and $\left|f^{\prime}(x)\right| \leq M, x \in[a, b]$, 
Tunç Journal of Inequalities and Applications 2013, 2013:326

Page 6 of 10

then

$$
\begin{aligned}
& \left|f(x)-\frac{1}{b-a} \int_{a}^{b} f(u) d u\right| \\
& \quad \leq \frac{\sqrt[q]{2} M}{2(b-a)}\left((x-a)^{2}+(b-x)^{2}\right)\left(\int_{0}^{1}\left(h\left(t^{2}\right)+h\left(t-t^{2}\right)\right) d t\right)^{\frac{1}{q}}
\end{aligned}
$$

for each $x \in[a, b]$.

Proof Suppose that $q \geq 1$. From Lemma 1 and using the power mean inequality, we have

$$
\begin{aligned}
\mid f(x) & -\frac{1}{b-a} \int_{a}^{b} f(u) d u \mid \\
\leq & \frac{(x-a)^{2}}{b-a} \int_{0}^{1} t\left|f^{\prime}(t x+(1-t) a)\right| d t+\frac{(b-x)^{2}}{b-a} \int_{0}^{1} t\left|f^{\prime}(t x+(1-t) b)\right| d t \\
\leq & \frac{(x-a)^{2}}{b-a}\left(\int_{0}^{1} t d t\right)^{1-\frac{1}{q}}\left(\int_{0}^{1} t\left|f^{\prime}(t x+(1-t) a)\right|^{q} d t\right)^{\frac{1}{q}} \\
& +\frac{(b-x)^{2}}{b-a}\left(\int_{0}^{1} t d t\right)^{1-\frac{1}{q}}\left(\int_{0}^{1} t\left|f^{\prime}(t x+(1-t) b)\right|^{q} d t\right)^{\frac{1}{q}} .
\end{aligned}
$$

Since $\left|f^{\prime}\right|^{q}$ is $h$-convex, we have

$$
\begin{aligned}
\int_{0}^{1} t\left|f^{\prime}(t x+(1-t) a)\right|^{q} d t & \leq \int_{0}^{1}\left[\operatorname{th}(t)\left|f^{\prime}(x)\right|^{q}+t h(1-t)\left|f^{\prime}(a)\right|^{q}\right] d t \\
& \leq\left|f^{\prime}(x)\right|^{q} \int_{0}^{1} h(t) h(t) d t+\left|f^{\prime}(a)\right|^{q} \int_{0}^{1} h(t) h(1-t) d t \\
& \leq M^{q}\left[\int_{0}^{1} h\left(t^{2}\right) d t+\int_{0}^{1} h\left(t-t^{2}\right) d t\right] .
\end{aligned}
$$

Similarly, we can observe that

$$
\begin{aligned}
\int_{0}^{1} t\left|f^{\prime}(t x+(1-t) b)\right|^{q} d t & \leq\left|f^{\prime}(x)\right|^{q} \int_{0}^{1} h(t) h(t) d t+\left|f^{\prime}(b)\right|^{q} \int_{0}^{1} h(t) h(1-t) d t \\
& \leq M^{q}\left\{\int_{0}^{1} h\left(t^{2}\right) d t+\int_{0}^{1} h\left(t-t^{2}\right) d t\right\} .
\end{aligned}
$$

Therefore, we deduce

$$
\begin{aligned}
\mid f(x) & -\frac{1}{b-a} \int_{a}^{b} f(u) d u \mid \\
\leq & \frac{(x-a)^{2}}{b-a}\left(\frac{1}{2}\right)^{1-\frac{1}{q}}\left(M^{q} \int_{0}^{1}\left(h\left(t^{2}\right)+h\left(t-t^{2}\right)\right) d t\right)^{\frac{1}{q}} \\
& +\frac{(b-x)^{2}}{b-a}\left(\frac{1}{2}\right)^{1-\frac{1}{q}}\left(M^{q} \int_{0}^{1}\left(h\left(t^{2}\right)+h\left(t-t^{2}\right)\right) d t\right)^{\frac{1}{q}}
\end{aligned}
$$




$$
\begin{aligned}
& =M\left(\frac{1}{2}\right)^{1-\frac{1}{q}}\left(\int_{0}^{1}\left(h\left(t^{2}\right)+h\left(t-t^{2}\right)\right) d t\right)^{\frac{1}{q}}\left(\frac{(x-a)^{2}+(b-x)^{2}}{(b-a)}\right) \\
& =\sqrt[q]{2} M\left(\int_{0}^{1}\left(h\left(t^{2}\right)+h\left(t-t^{2}\right)\right) d t\right)^{\frac{1}{q}}\left(\frac{(x-a)^{2}+(b-x)^{2}}{2(b-a)}\right)
\end{aligned}
$$

and the proof is completed.

\section{Remark 4}

(i) In the above inequalities, one can establish several midpoint-type inequalities by letting $x=\frac{a+b}{2}$.

(ii) In Theorem 4, if we choose

(a) $x=\frac{a+b}{2}$, then we obtain

$$
\begin{aligned}
& \left|f\left(\frac{a+b}{2}\right)-\frac{1}{b-a} \int_{a}^{b} f(u) d u\right| \\
& \quad \leq \frac{\sqrt[q]{2} M(b-a)}{4}\left(\int_{0}^{1}\left(h\left(t^{2}\right)+h\left(t-t^{2}\right)\right) d t\right)^{\frac{1}{q}},
\end{aligned}
$$

(b) $x=a$, then we obtain

$$
\left|f(a)-\frac{1}{b-a} \int_{a}^{b} f(u) d u\right| \leq \frac{\sqrt[q]{2} M(b-a)}{2}\left(\int_{0}^{1}\left(h\left(t^{2}\right)+h\left(t-t^{2}\right)\right) d t\right)^{\frac{1}{q}}
$$

(c) $x=b$, then we obtain

$$
\left|f(b)-\frac{1}{b-a} \int_{a}^{b} f(u) d u\right| \leq \frac{\sqrt[q]{2} M(b-a)}{2}\left(\int_{0}^{1}\left(h\left(t^{2}\right)+h\left(t-t^{2}\right)\right) d t\right)^{\frac{1}{q}} .
$$

The following result holds for $h$-concave functions.

Theorem 5 Let $h: J \subseteq \mathbb{R} \rightarrow \mathbb{R}$ be a nonnegative and super-additive function, let $f: I \subseteq$ $\mathbb{R} \rightarrow \mathbb{R}$ be a differentiable mapping on $I^{\circ}$ such that $f^{\prime} \in L[a, b]$, where $a, b \in I$ with $a<b$. If $\left|f^{\prime}\right|^{q}$ is an h-concave function on $[a, b], p, q>1, \frac{1}{p}+\frac{1}{q}=1, h(t) \geq t$, then

$$
\begin{aligned}
& \left|f(x)-\frac{1}{b-a} \int_{a}^{b} f(u) d u\right| \\
& \quad \leq \frac{1}{\sqrt[q]{2}(p+1)^{\frac{1}{p}} h^{\frac{1}{q}\left(\frac{1}{2}\right)}}\left[\frac{(x-a)^{2}}{b-a}\left|f^{\prime}\left(\frac{x+a}{2}\right)\right|+\frac{(b-x)^{2}}{b-a}\left|f^{\prime}\left(\frac{x+b}{2}\right)\right|\right]
\end{aligned}
$$

for each $x \in[a, b]$

Proof Suppose that $p>1$. From Lemma 1 and using Hölder's inequality, we can write

$$
\begin{aligned}
& \left|f(x)-\frac{1}{b-a} \int_{a}^{b} f(u) d u\right| \\
& \quad \leq \frac{(x-a)^{2}}{b-a} \int_{0}^{1} t\left|f^{\prime}(t x+(1-t) a)\right| d t+\frac{(b-x)^{2}}{b-a} \int_{0}^{1} t\left|f^{\prime}(t x+(1-t) b)\right| d t
\end{aligned}
$$




$$
\begin{aligned}
\leq & \frac{(x-a)^{2}}{b-a}\left(\int_{0}^{1} t^{p} d t\right)^{\frac{1}{p}} \cdot\left(\int_{0}^{1}\left|f^{\prime}(t x+(1-t) a)\right|^{q} d t\right)^{\frac{1}{q}} \\
& +\frac{(b-x)^{2}}{b-a}\left(\int_{0}^{1} t^{p} d t\right)^{\frac{1}{p}} \cdot\left(\int_{0}^{1}\left|f^{\prime}(t x+(1-t) b)\right|^{q} d t\right)^{\frac{1}{q}} .
\end{aligned}
$$

However, since $\left|f^{\prime}\right|^{q}$ is $h$-concave, using inequality (1.10), we have

$$
\left(\int_{0}^{1}\left|f^{\prime}(t x+(1-t) a)\right|^{q} d t\right) \leq \frac{1}{2 h\left(\frac{1}{2}\right)}\left|f^{\prime}\left(\frac{x+a}{2}\right)\right|^{q}
$$

and

$$
\left(\int_{0}^{1}\left|f^{\prime}(t x+(1-t) b)\right|^{q} d t\right) \leq \frac{1}{2 h\left(\frac{1}{2}\right)}\left|f^{\prime}\left(\frac{x+b}{2}\right)\right|^{q} .
$$

By combining the numbered inequalities above, we obtain

$$
\begin{aligned}
\mid f(x) & -\frac{1}{b-a} \int_{a}^{b} f(u) d u \mid \\
\leq & \frac{(x-a)^{2}}{b-a} \frac{1}{(p+1)^{\frac{1}{p}}}\left(\frac{1}{2 h\left(\frac{1}{2}\right)}\right)^{\frac{1}{q}}\left|f^{\prime}\left(\frac{x+a}{2}\right)\right| \\
& +\frac{(b-x)^{2}}{b-a} \frac{1}{(p+1)^{\frac{1}{p}}}\left(\frac{1}{2 h\left(\frac{1}{2}\right)}\right)^{\frac{1}{q}}\left|f^{\prime}\left(\frac{x+b}{2}\right)\right| \\
= & \frac{1}{\sqrt[q]{2}(p+1)^{\frac{1}{p}} h^{\frac{1}{q}}\left(\frac{1}{2}\right)}\left[\frac{(x-a)^{2}}{b-a}\left|f^{\prime}\left(\frac{x+a}{2}\right)\right|+\frac{(b-x)^{2}}{b-a}\left|f^{\prime}\left(\frac{x+b}{2}\right)\right|\right] .
\end{aligned}
$$

The proof is completed.

A midpoint-type inequality for functions whose derivatives in absolute value are $h$-concave may be established from the result above as follows.

Corollary 3 In (2.5), if we choose $x=\frac{a+b}{2}$, then we get

$$
\begin{aligned}
& \left|f\left(\frac{a+b}{2}\right)-\frac{1}{b-a} \int_{a}^{b} f(u) d u\right| \\
& \quad \leq \frac{b-a}{\sqrt[q]{2^{2 q+1}}(p+1)^{\frac{1}{p}} h^{\frac{1}{q}}\left(\frac{1}{2}\right)}\left[\left|f^{\prime}\left(\frac{3 a+b}{4}\right)\right|+\left|f^{\prime}\left(\frac{a+3 b}{4}\right)\right|\right] .
\end{aligned}
$$

For instance, if $h(t)=t$, then we obtain

$$
\begin{aligned}
& \left|f\left(\frac{a+b}{2}\right)-\frac{1}{b-a} \int_{a}^{b} f(u) d u\right| \\
& \quad \leq \frac{b-a}{4(p+1)^{\frac{1}{p}}}\left[\left|f^{\prime}\left(\frac{3 a+b}{4}\right)\right|+\left|f^{\prime}\left(\frac{a+3 b}{4}\right)\right|\right],
\end{aligned}
$$

where $\left|f^{\prime}\right|^{q}$ is an h-concave function on $[a, b], p, q>1$. 


\section{Applications to special means}

We consider the means for arbitrary positive numbers $a, b(a \neq b)$ as follows.

The arithmetic mean:

$$
A(a, b)=\frac{a+b}{2}
$$

The generalized log-mean:

$$
L_{p}(a, b)=\left[\frac{b^{p+1}-a^{p+1}}{(p+1)(b-a)}\right]^{\frac{1}{p}}, \quad p \in \mathbb{R} \backslash\{-1,0\}
$$

The identric mean:

$$
I(a, b)=\frac{1}{e}\left(\frac{b^{b}}{a^{a}}\right)^{\frac{1}{b-a}}
$$

Now, using the result of Section 2, we give some applications to special means of real numbers.

In [11], the following example is given.

Example 1 [11] Let $h$ be a function defined by $h(x)=(c+x)^{p-1}, x \geq 0$. If $c=0$, then the function $h$ is multiplicative. If $c \geq 1$, then for $p \in(0,1)$ the function $h$ is super-multiplicative and for $p>1$ the function $h$ is sub-multiplicative.

Hence, for $c=1, p \in(0,1)$, we have $h(t)=(1+t)^{p-1}, t \geq 0$, is super-multiplicative. Let $f(x)=x^{n}, x>0,|n| \geq 2$, be an $h$-convex function.

Proposition 1 Let $0<a<b, p \in(0,1)$ and $|n| \geq 2$. Then

$$
\left|A^{n}(a, b)-L_{n}^{n}(a, b)\right| \leq \frac{M(b-a)}{4}\left[\int_{0}^{1}\left(1+t^{2}\right)^{p-1} d t+\int_{0}^{1}\left(1+t-t^{2}\right)^{p-1} d t\right] .
$$

Proof The inequality is derived from (2.1) with $x=\frac{a+b}{2}$ applied to the $h$-convex functions $f: \mathbb{R} \rightarrow \mathbb{R}, f(x)=x^{n},|n| \geq 2$, and $h: \mathbb{R} \rightarrow \mathbb{R}, h(t)=(1+t)^{p-1}, p \in(0,1)$. The details are disregarded.

Proposition 2 Let $0<a<b, p \in(0,1), q>1$ and $|n| \geq 2$. Then

$$
\left|A^{n}(a, b)-L_{n}^{n}(a, b)\right| \leq \frac{\sqrt[p]{2} M(b-a)}{8}\left[\int_{0}^{1}\left(1+t^{2}\right)^{p-1} d t+\int_{0}^{1}\left(1+t-t^{2}\right)^{p-1} d t\right]^{\frac{1}{q}}
$$

Proof The inequality is derived from (2.3) with $x=\frac{a+b}{2}$ applied to the $h$-convex functions $f: \mathbb{R} \rightarrow \mathbb{R}, f(x)=x^{n},|n| \geq 2$, and $h: \mathbb{R} \rightarrow \mathbb{R}, h(t)=(1+t)^{p-1}, p \in(0,1)$. The details are disregarded.

Proposition 3 Let $0<a<b$ and $p, q>1$. Then we have

$$
|\ln (A(a, b)+1)-(b-a) \ln I(a+1, b+1)| \leq \frac{b-a}{4(p+1)^{\frac{1}{p}}}\left[\frac{1}{3 a+b+4}+\frac{1}{a+3 b+4}\right]
$$


Proof The inequality is derived from (2.10) applied to the concave function $f:[a, b] \rightarrow \mathbb{R}$, $f(x)=\ln (x+1)$. The details are disregarded.

\section{Competing interests}

The author declares that they have no competing interests.

\section{Acknowledgements}

The author gives his warm thanks to the editor and the authors for their precious papers in the reference list.

Received: 30 January 2013 Accepted: 1 July 2013 Published: 16 July 2013

\section{References}

1. Dragomir, SS, Rassias, TM (eds.): Ostrowski Type Inequalities and Applications in Numerical Integration. Kluwer Academic, Dordrecht (2002)

2. Alomari, M, Darus, M: Some Ostrowski type inequalities for convex functions with applications. RGMIA Res. Rep. Coll. 13(1), Article No. 3 (2010)

3. Alomari, M, Darus, M: Some Ostrowski type inequalities for quasi-convex functions with applications to special means. RGMIA Res. Rep. Coll. 13(2), Article No. 3 (2010)

4. Alomari, M, Darus, M, Dragomir, SS, Cerone, P: Ostrowski type inequalities for functions whose derivatives are s-convex in the second sense. Appl. Math. Lett. 23, 1071-1076 (2010)

5. Cerone, P, Dragomir, SS: Ostrowski type inequalities for functions whose derivatives satisfy certain convexity assumptions. Demonstr. Math. 37(2), 299-308 (2004)

6. Barnett, NS, Cerone, P, Dragomir, SS, Pinheiro, MR, Sofo, A: Ostrowski type inequalities for functions whose modulus of derivatives are convex and applications. RGMIA Res. Rep. Coll. 5(2), Article No. 1 (2002).

http://www.rgmia.org/papers/v5n2/Paperwapp2q.pdf

7. Dragomir, SS, Sofo, A: Ostrowski type inequalities for functions whose derivatives are convex. In: Proceedings of the 4th International Conference on Modelling and Simulation, Victoria University, Melbourne, Australia, 11-13 November 2002. RGMIA Res. Rep. Coll. 5, supp., Article No. 30 (2002). http://www.rgmia.org/papers/v5e/OTIDC2_col.pdf

8. Godunova, EK, Levin, VI: Neravenstva dlja funkcii sirokogo klassa, soderzascego vypuklye, monotonnye i nekotorye drugie vidy funkcii. In: Vycislitel. Mat. i Fiz. Mezvuzov. Sb. Nauc. Trudov, pp. 138-142. MGPI, Moscow (1985)

9. Dragomir, SS, Pečarić, J, Persson, LE: Some inequalities of Hadamard type. Soochow J. Math. 21, 335-341 (1995)

10. Hudzik, H, Maligranda, L: Some remarks on s-convex functions. Aequ. Math. 48, 100-111 (1994)

11. Varošanec, S: On h-convexity. J. Math. Anal. Appl. 326(1), 303-311 (2007)

12. Alzer, H: A superadditive property of Hadamard's gamma function. Abh. Math. Semin. Univ. Hamb. 79, 11-23 (2009)

13. Sarıkaya, MZ, Sağlam, A, Yıldırım, H: On some Hadamard-type inequalities for $h$-convex functions. J. Math. Inequal. 2(3), 335-341 (2008)

14. Bombardelli, $M$, Varošanec, S: Properties of $h$-convex functions related to the Hermite-Hadamard-Fejér inequalities. Comput. Math. Appl. 58, 1869-1877 (2009)

15. Burai, P, Hazy, A: On approximately h-convex functions. J. Convex Anal. 18(2), 447-454 (2011)

16. Özdemir, ME, Gürbüz, M, Akdemir, AO: Inequalities for $h$-convex functions via further properties. RGMIA Res. Rep. Coll. 14, Article No. 22 (2011)

doi:10.1186/1029-242X-2013-326

Cite this article as: Tunç: Ostrowski-type inequalities via $h$-convex functions with applications to special means. Journal of Inequalities and Applications 2013 2013:326.

\section{Submit your manuscript to a SpringerOpen ${ }^{\circ}$ journal and benefit from:}

- Convenient online submission

- Rigorous peer review

- Immediate publication on acceptance

- Open access: articles freely available online

- High visibility within the field

- Retaining the copyright to your article 